\title{
Cultura y Medios. De la escuela de Frankfurt a la Convergencia Multimedia
}

\author{
Dra. Soledad Ruano López \\ Profesora del Área de Comunicación Audiovisual \\ Universidad de Extremadura
}

\section{Resumen:}

Los dos términos que encabezan el artículo, Cultura y Medios, son dos conceptos inseparables que atienden a realidades muy complejas, y cuyas relaciones y diferencias se establecen según las épocas. No son cuestiones novedosas a analizar, sobre ellos se han escrito multitud de páginas. En este artículo vamos a ahondar en dicha extensión cultural y comunicacional, desde distintas perspectivas. En la primera vamos a evocar la etapa más tradicional, poniendo especial énfasis en las nociones de cultura e industria cultural; en la segunda perspectiva haremos hincapié en la tecnológia, o el negocio de las telecomunicaciones y en la tercera y última, trataremos de acercarnos a la actualidad, donde ambos ámbitos convergen en el sector multimedia.

\section{Abstract}

Both terms that head the article, Culture and Means, they are two inseparable concepts that, they take care of very complex realities, whose relations and differences settle down according to the times. They are not novel questions to analyze, on them they have been written multitude of pages. In this article we are going to go deep in this cultural and communicational extension, from different perspective. In first we are going to evoke the most traditional stage, putting special emphasis in the culture slight knowledge and cultural industry; in the second perspective we will insist on the technological one, or the business of the telecommunications and in the third and last one, we will try to approach us the present time, where both scopes converge in the sector mutimedia.

Palabras clave: Cultura, comunicación, medios, industrias culturales, multimedia, Internet.

Key words: Culture, communication, means, cultural industries, multimedia, Internet. 
Cultura y Medios...

\section{INTRODUCCIÓN}

$E$

xisten muchas formas de definir la cultura, y por tanto, no hay criterios unívocos a este respecto. A las definiciones menos ambiciosas de cultura, que tienden a considerarla, en términos muy generales, como al conjunto de rasgos distintivos que dan cohesión a una comunidad o grupo social y que generan el ámbito para su permanente renovación y sus heterogéneas manifestaciones, hay que añadir los conceptos filosóficos, sociológicos, históricos, antropológicos, industriales, etc., además de los nuevos sufijos y prefijos que se le anexan permanentemente, así como adjetivos y términos como transculturación, aculturación; poscultura, subcultura y contracultura; multicultural y pluricultural, etc. Esto es sólo un ejemplo que se puede añadir a la compleja tarea de definir qué es cultura. De tal manera que, un concepto tan amplio, ambiguo y ambicioso debe ser usado con sumo cuidado. Además, "en la actualidad existe una tendencia a designar con este término todas las actividades que realiza el hombre, aún las más negativas: cultura de la droga, cultura de la violencia o cultura de la muerte" .

Según Raymond Williams, el concepto de cultura en un sentido más corriente y popular se ha solidificado en tres acepciones: "Podemos distinguir una gama de significados que va: desde 1) un estado de desarrollo de la mente, como es el caso de una persona con cultura, una persona culta; hasta 2) los procesos de este desarrollo, como es el caso de los intereses culturales y las actividades culturales; y 3) los medios de estos procesos, como las artes y las obras humanas intelectuales en la cultura. Este último es el significado más común en nuestra propia época, aunque todos se utilizan" .

Un concepto que, como estamos viendo, es amplio, y por ello, no se deja encuadrar fácilmente en una definición unívoca. A esto hay que añadir para ampliar más el análisis las distintas definiciones existentes entre cultura de élite y cultura de masas.

El sociólogo Luis Escobar hace una distinción básica entre cultura superior o de élite y cultura de masas, basándose en las creaciones artísticas y literarias de los pueblos. Desde su perspectiva, cultura comprende todos los procesos y valores, tanto sociales como materiales, que integran una civilización, llegando a resumir toda la experiencia vital de cada individuo.

Para Escobar, la cultura superior se vincula al concepto más individualista de la cultura, el que hace referencia a determinado dominio intelectual y artístico, en tanto que cultura de masas alude a los aspectos de la vida de una sociedad: política, religión, costumbres, ética, ciencia, arte, técnica; es decir, todo aquello que la tipifica, la distingue y le permite subsistir y progresar. Pero las dicotomías entre cultura de elite y cultura de masas van a comenzar a tornarse algo difusas

\footnotetext{
1 RODRÍGUEZ PASTORIZA, F., Cultura y televisión: una relación de conflicto. Barcelona, Gedisa, 2003, p.12.

${ }^{2}$ WILLIAMS, R., Sociología de la cultura. Barcelona, Paidós, 1994, p.11.
} 
con la aparición de los medios masivos de comunicación. La cultura de élite no desaparece con el surgimiento de la cultura de masas, sino que, muy por el contrario, se suma a la cultura creada por y para la televisión ${ }^{3}$. La cultura de masas, que no excluye a la elite pero sí incluye a muchas más franjas de la sociedad por ser una cultura comercializada, genera que la mayoría de la población alcance la producción estandarizada de la cultura a través de los medios de comunicación. Como consecuencia de ello, la cultura se democratiza y hay, en un sentido, mayor acceso al hecho cultural. La acción de los medios de comunicación ha hecho que la cultura pase a ser un patrimonio de las masas, y no únicamente de una élite.

Para finalizar con este panorama general, el semiólogo Umberto Eco afirmaba que existen dos posturas ante la cultura de masas: por un lado, los apocalípticos para los cuales la cultura es un hecho aristocrático, produciendo su extensión una anticultura; y, por otro, los integrados, para los cuales estamos en una época de extensión de la cultura, beneficiosa para todos, no planteándose si esta extensión nace de abajo o de arriba. «El Apocalipsis es una obsesión del dissenter, la integración es la realidad concreta de aquellos que no disienten", En el fondo, argumentaba Eco, la posición apocalíptica es un consuelo para el lector, que creen formar parte de una pequeña comunidad de críticos elevada sobre la vulgaridad de la cultura de masas. Lector y autor serían representantes de la cultura elitista o aristocrática. El término cultura de masas goza de la imprecisión de no definir lo que es masa ni lo que es cultura. Los apocalípticos, además, no suelen realizar un verdadero análisis de los contenidos culturales, limitándose a rechazarla como un todo. Y, por otro lado, no investigan las audiencias como tales, sino que las caracterizan con el estereotipo del hombre masa.

En suma son numerosas las referencias que podemos encontrar sobre el término cultura y sus acepciones, y todo esto nos lleva ineluctablemente a una precaución inicial que nos condicionará a utilizar el término con especial cuidado, al ser vocablo polisémico y al presentar multitud de matices.

El segundo término que entra en juego es el término mass media, término anglosajón, que ha dado en llamar Media a los medios de comunicación en tanto que son instrumentos artificiales en el proceso de comunicación. Los media conforman un conjunto de actividades económicas, teniendo cada media una actividad económica diferente, por lo que es posible clasificarlos en subconjuntos como: prensa, cine, radio, televisión, y ahora Internet.

\footnotetext{
${ }^{3}$ ESCOBAR DE LA SERNA, L., Comunicación, Información y Cultura de Masas. Madrid, Secretaría General Técnica del Ministerio de Cultura, 1980, pp. 7.

${ }^{4}$ ECO, U., Apocalípticos e integrados. Barcelona, Lumen, 1993, p.28.
} 


\section{CONCEPCIÓN CLÁSICA DE LA CULTURA: ESCUELA DE FRANKFURT}

Desde principios del siglo XX, los conceptos cultura e industria han estado cerca. Malraux, en la década de 1960, sintetiza muy bien esta realidad: "El cine es un arte, pero también es una industria". En un registro de corte más teórico, Pastoriza postula algo similar: “(...) La aparición de la televisión ha venido a reforzar los lazos entre industria ${ }_{5}$ cultura y a potenciar la utilización de un nuevo término: el de "industria cultural"

Fue la Escuela de Frankfurt la que teorizó de forma más acabada sobre la gran transformación cultural comenzada en el siglo XX debido a la acción de los medios de comunicación, donde la cultura estaba adquiriendo un carácter industrial. El punto de vista de la Escuela de Frankfurt, por su novedoso objeto de estudio para la época, por la originalidad de sus planteamientos y por su capacidad para presentar problemas actuales, es imprescindible para analizar los impactos de la cultura industrializada, así como lo es su preocupación por el análisis de los contenidos culturales o la percepción que tenía de que el cambio social conlleva inseparablemente un cambio cultural, hoy plenamente vigente. Más allá de algunas exageraciones, la Escuela de Frankfurt (Benjamin 1973, Adorno y Horkheimer, 1969) acertó al establecer una diferencia entre la cultura tradicional y la cultura industrializada, y comprender ésta última como parte del modelo capitalista de producción, definiendo la industria cultural como propia de la cultura de masas. De tal manera que el objeto de estudio de la Escuela de Frankfurt era la sociedad industrial avanzada y la industria de la cultura que en ella había surgido.

Los trabajos que realizaron Horkheimer y Adorno vivieron una reactualización en los años sesenta a través de Herbert Marcuse, quien, según algunos teóricos actuales como Armand y Michèle Mattelart, fue la figura más brillante de la Escuela de Frankfurt. En esos años realizó uno de sus mejores trabajos, El Hombre Unidimensional, escrita en 1964, que constituía una crítica a la cultura y la civilización burguesa. El heredero de esta corriente en nuestros días es el filósofo alemán Jürgen Habermas, quien, en el libro El Espacio Público, prosigue el trabajo de la escuela en el nivel filosófico y sociológico.

Además de la Escuela de Frankfurt, en la que, según se ve, se adopta una de las actitudes más críticas y negativas ante el fenómeno de la sociedad de masas y su cultura, existen otras corrientes que siguen este perfil objetor, tales como la corriente constituida por los críticos norteamericanos más radicales que fijaron su discusión en los años cincuenta y sesenta en torno a la industria cultural, a la cultura de masas y a la sociedad de masas. Entre ellos están Dwight Macdonald, quien, con los términos masscult y midcult, critica la cultura de masas y la vulgaridad intelectual de sus consumidores. Edward Shils, por su lado, y partiendo de criterios estéticos, aporta una distinción entre cultura refinada, cultura mediocre y cultura brutal. También debemos contar otras corrientes que intentan llegar a la

5 RODRÍGUEZ PASTORIZA, F., Cultura y televisión: una relación de conflicto. Barcelona, Gedisa, 2003, p.17. 
crítica racional de las industrias culturales como Daniel Bell y, por último, la de los sociólogos académicos que se han dedicado a elaborar los métodos relevantes del fenómeno, como Lazarsfeld y Merton.

Ambos autores desmitifican la obsesión de los críticos radicales ante una cultura de masas que obliga al ciudadano a plegarse a sus deseos, pero advierten que los medios de comunicación de masas representan un poderoso instrumento, tanto para el bien como para el mal, ya que son medios aptos para la propaganda y de notable ubicuidad y poder potencial. Ambos autores ponen de manifiesto, por una parte, la influencia y capacidad manipuladora que los medios poseen en la opinión pública y, por otra, la presión que pueden ejercer al poner al descubierto anormalidades de cualquier índole.

Dwight Macdonald, con su mencionado trabajo sobre masscult y midcult ${ }^{6}$, es el ejemplo más interesante de esta tendencia. Durante casi dos siglos, la cultura occidental ha sostenido a su vez dos manifestaciones culturales: por un lado la superior, producida por los libros de textos, y por otro la narrativa, fabricada para el mercado. A esta última se la homologa con el término de cultura de masas, o como la llama Macdonald, masscult, que en realidad designa el ámbito de la cultura de masas de nivel inferior, despreocupada de los valores de la alta cultura, y cuyos agentes son la radio o la televisión. La masscult es un fenómeno que se diferencia tanto de la alta cultura como de la cultura popular, en la medida en que, mientras ésta nace desde abajo, como un producto autóctono proveniente del pueblo para satisfacer sus propias exigencias y necesidades, la masscult nacerá desde arriba, como negocio, dentro de una lógica de la oferta y la demanda. La masscult, desde el punto de vista del consumo y de la producción, tiene, desde Macdonald, algunas ventajas estratégicas respecto de la cultura superior; por ejemplo, que al carecer el público de las competencias necesarias para acceder a una obra de arte culta, se siente más satisfecho y más cómodo con la producción mediocre de la cultura de masas. Pero tiene, también, un agravante que resulta ser mucho peor que aquella ventaja, no es arte, sino su caricatura.

Pero no todos los teóricos van por estos derroteros. Daniel Bell, un racionalizador del sistema postindustrial (1930), es uno de los primeros en atacar a los críticos más radicales de la época como Macdonald. La mayor parte de la crítica radical de la sociedad contemporánea se concentraba sobre la injusticia social y económica, pero en las décadas siguientes, con el surgimiento del estado de bienestar, la crítica radical perdió impulso y fuerza de choque. Entre 1940 y 1950 la crítica política se transformó en crítica cultural.

Daniel Bell lanza y va perfeccionando, entre la década de 1960 y la de 1970, el concepto de sociedad postindustrial para denominar el advenimiento de la nueva sociedad construida con las tecnologías de la inteligencia y la industria de la

\footnotetext{
6 MACDONALD, D., "Masscult y Midcult", en La industria de la cultura, Madrid, Alberto Corazón, 1969.
} 
información, materia prima del futuro. Entre Bell y los integrantes nombrados de la Escuela de Frankfurt pueden evidenciarse algunos puntos de encuentro, sobre todo en lo referido al enfrentamiento de la escuela con la visión neoliberal de la cultura industrializada, y de su crítica a la industria cultural.

Interesa, por ello, analizar más cuidadosamente las aportaciones de la Escuela de Frankfurt a la crítica de la industria cultural. El origen del término industria cultural se remonta a dicha escuela. A mediados de los años cuarenta, Adorno y Horkheimer, ambos filósofos, crean el concepto de industria cultural y lo acuñan para explicar un cambio en los procesos de transmisión de la cultura, cambio que se estaba rigiendo por el principio de mercantilización y que modificaba de manera sustancial su carácter tradicional. Los dos filósofos señalaron y analizaron, en su conocida obra la Dialéctica de la llustración, la transformación que hoy están sufriendo los medios de comunicación de masas y el carácter industrial que estaba adquiriendo la producción de la cultura en nuestra sociedad. Se trataba de expandir el análisis marxista de la economía hacia la producción de lo que podríamos denominar bienes culturales. En este sentido, se manifestaron en contra de la mercantilización de la cultura, poniendo en evidencia las consecuencias destructoras y desastrosas de esa mercantilización respecto de los contenidos culturales y artísticos.

Por su parte, el filósofo judeoalemán Walter Benjamin, muy cercano a la Escuela de Frankfurt, comprende que la forma en que el arte se convierte en mercancía ocurre gracias a la capacidad industrial de repetirlo, de hacer copias. Su artículo El arte en la era de la reproductibilidad técnica se enfrenta ante la paradoja de que una obra que es por definición única, un cuadro por ejemplo, se puede fotografiar y vender millones de veces. Así, su aura, su aspecto artístico que le viene dado por ser absolutamente único y que lo acerca a los elementos culturales, se desvanece. La repetición de la obra significa trivializarla y lo mismo ocurre con la descontextualización. Estos dos aspectos son necesarios para convertir algo en mercancía porque sólo si se puede repetir y vender en cualquier contexto entonces se convierte en tal.

A pesar de todo, Benjamin fue en dirección distinta de la de Adorno y Horkheimer, y consideró que la fotografía y el cine, el jazz y la música popular, podrían servir para modificar la conciencia de la masa, precisamente por su posibilidad de difusión masiva. Donde Benjamin veía una oportunidad de usurparle al capitalismo la herramienta de control social para contribuir a dar conciencia a las masas, Adorno veía, en esas nuevas tecnologías, la total imposibilidad de darles un destino en contra del sistema. La teoría adorniana, sin embargo, tuvo mucha influencia en las segundas vanguardias como el pop o el conceptual, en la obra repetida o serialización (pop), en la desmaterialización o ideación del arte (conceptual), etc.

Eduardo Subirats, en su trabajo Culturas Virtuales, parte de la crítica que Adorno y Benjamin hacen de los medios cuando los acusan de estetizar la cultura. Estetizar la política, por ejemplo, implica hacerle perder su carácter real y convertirla en un espectáculo y no en algo concreto. Quizás, en relación con esto, el caso 
más notable fue el de François Mitterrand y su política museística. Espectacularizar todo es una consecuencia de la descontextualización. De esta crítica al carácter descontextualizador y trivializador de la sociedad mediática proviene la segunda hornada de críticos de la industria cultural como los situacionistas (como Guy Débord, su máximo teórico). La industria cultural, desde esta perspectiva, vacía de contenidos, se fija sólo en la forma, a fin de que el consumo de sus productos sea masivo. Todo se convierte en espectáculo, performance, y así, por ejemplo, la guerra es una manera de crear contenidos para una industria cultural, porque se puede estetizar. Consecuencia de esta lógica, es la célebre frase de Jean Baudrillard, "La guerra del Golfo no ha tenido lugar".

Zallo, otro seguidor de la Escuela de Frankfurt y especialmente de Walter Benjamin, pone de manifiesto que la industria cultural: "(...) constaba así un cambio radical tanto en la forma de producción como del lugar social de la cultura. Sin embargo, lo nuevo en la segunda mitad del S XX, no fue la mercantilización de la cultura, -ya estaba presente en la cultura tradicional de las artes plásticas o teatrales-, tampoco lo fue la aplicación de procedimientos industriales a la producción cultural -ya implantados en la industria editorial, y emergentes en ese momento en el cine, la fonografía y la radio-, ni siquiera lo fue la estratificación económica o educacional en el acceso a la cultura, que en esa época empezaba a paliarse de forma relativa con la intervención pública bajo la égida del Estado del Bienestar. El cambio real lo tejieron dos factores: la expansión del mercado de la cultura como forma específica de extensión de la cultura, con un tipo de producción cultural, la cultura de masas, y la aplicación de los principios de la organización del trabajo taylorista $^{7}$, y más recientemente neotaylorista, a la producción cultural" ${ }^{8}$.

Sin embargo, según nos lo explica Murciano, Morin demuestra “(...) cómo la división del trabajo y la tecnología no son incompatibles con la creación artística, y que ni la serialización ni la estandarización anulan la creatividad. Industria Cultural es para Morin no tanto la racionalidad de que informa esa cultura cuanto el modelo peculiar que organiza los nuevos procesos de producción cultural, esto es, el conjunto de mecanismos y operaciones a través de los cuales la creación se transforma en producción","

Para Adorno y Horkheimer, fuera de esta arista de pensamiento, la industria cultural dejaba de ser un servicio social, desde el momento que se habla de rentabilidad económica del producto. Las industrias culturales no podían ser o seguir haciéndose pasar por arte cuando en realidad eran negocios "(...) se

\footnotetext{
${ }^{7}$ Taylorismo: Frederick Winslow Taylor, ingeniero estadounidense. En el taylorismo, la organización del trabajo persigue el aumento de la productividad mediante la máxima división de funciones, la especialización del trabajador y el control del tiempo necesario para cada tarea.

${ }^{8}$ ZALLO, R., El mercado de la cultura europea. Estructura económica y política de la comunicación. Donostia (Guipúzcoa), Gakoa, 1992, p.10.

9 MURCIANO, M., "Cuestiones Metodológicas en la Investigación sobre Industrias Culturales". Análisi, № 13, 1990, pp. 15-26.
} 
autodefinen como industrias y las cifras publicadas de las rentas, quitan toda duda de la necesidad social del producto" ${ }^{10}$.

Adorno y Horkheimer calificaban y acusaban a las industrias culturales de industrias de la diversión: "Resulta por los menos dudoso que la industria cultural cumpla con la tarea de divertir de la que abiertamente se jacta. Si la mayor parte de las radios y los cines callasen, es sumamente probable que los ciudadanos no sentirían en exceso su falta" ${ }^{\prime 1}$.

Resulta, y para concluir este apartado después de haber buceado sobre posiciones muy diversas, bastante discutible el hecho de que el arte se anule a partir del surgimiento de las industrias culturales en términos de tecnología o de la producción en serie. Si bien parte del pesimismo que Adorno y Horkheimer manifiestan para con la industria cultural es aún entendible, lo cierto es que el arte, ya inserto definitivamente en dicha industria, no ha desaparecido y tampoco se ha convertido únicamente en mercancía. El cine, considerado como arte unánimemente, es también una industria, y sin embargo, como lo profetizaba Benjamin, puede reencontrarse con lo artístico permanentemente. Esto les impidió, a Adorno y Horkheimer, ver otros aspectos distintos del arte y la tecnología que el mismo Benjamin, por ejemplo, sí reconocía. Para estos dos filósofos la relación que muchos productos de la cultura industrializada iban a establecer con la cultura popular o tradicional les fue ignorada. Tampoco valoraron que las nuevas industrias crearían las condiciones para nuevas expresiones artísticas, ni que los binomios cultura e industria, arte y capital, iban a alcanzar síntesis contradictorias debido a la democratización cultural y a la generación de nuevas formas culturales, por un lado, y a la irrupción directa del capital en el ámbito de la creación y la producción cultural, por otro.

\section{LA CULTURA COMO PRODUCTO. EL NEGOCIO DE LAS TELECOMUNICACIONES}

La segunda perspectiva sobre cultura que nos interesa involucra a la tecnología, aspecto en el que nos detendremos. Hoy, esta perspectiva es más prolífica en publicaciones que la analizada con anterioridad, que es una perspectiva, en mayor o menor medida, tradicional, heredera del pensamiento marxista.

En este aspecto los sectores de la información, las telecomunicaciones y la informática, empiezan a tomar posiciones, creando grupos y formando alianzas que, en la mayor parte de los casos, conducen a una fuerte concentración e internacionalización de los mercados. Este fenómeno se desarrolla con más fuerza a partir de la segunda mitad de los setenta y principio de los ochenta, y se caracteriza por una serie de transformaciones, como la convergencia tecnológica y

\footnotetext{
${ }^{10}$ HORKHEIMER, M. y ADORNO, Th., Dialéctica del lluminismo; La Industria Cultural. Iluminismo como mistificación de las masas. Buenos Aires, Sudamericana, 1988.

${ }^{11}$ Ibidem.
} 
la globalización de los medios de comunicación y sus contenidos. Produciéndose una ruptura con el pasado y anunciando una nueva etapa en cuanto al desarrollo económico, social y cultural, absolutamente diferente de su predecesora.

El sector de la comunicación y la cultura está conociendo cambios importantes: se están conociendo grandes mutaciones tecnológicas y productivas, además de espectaculares compras y fusiones entre los gigantes mundiales de la comunicación y la cultura, y que tienen una clara finalidad, disponer de una gran cantidad de contenidos de todo tipo para poder integrarlos en los canales de difusión y comercialización, quien controle los contenidos, mantendrá una posición estratégica de futuro.

Este sector se está beneficiando de la aplicación de las nuevas tecnologías, tanto por el lado productivo como por el lado del mercado, además de tener capitales bien colocados en las industrias de la electrónica y las telecomunicaciones que han podido dar el salto hacia las actividades de contenidos culturales o programas.

Para Zallo, este nuevo marco de acumulación ha terminado por definir el sector cultural con tres rasgos:

a) Es un sector en expansión tirado por firmas potentes y dinámicas, en general, sostenida o creciente salvo en momentos coyunturales. En los dos últimos decenios, son múltiples las circunstancias que hacen que los movimientos de capitales en el sistema comunicativo se encuentren en plena ebullición sin que, por el momento, se vislumbre una clara estabilización de las tendencias. Ello es válido tanto en los países en los que existe el dominio de servicio público (Europa) como en los que prima la economía de mercado, en este caso cultural (USA).

b) Es un sector atractivo para los capitales ociosos, en un momento de cambio y oportunidades, tanto si se trata de capitales arraigados y experimentados en el sector como para capitales recién llegados.

c) Es un sector que invita a estrategias ofensivas que no se detienen en las fronteras y que se proyecta en acelerados procesos de concentración de capital a niveles nacionales y transnacionales de cara a ocupar posiciones y acaparar mercados $^{12}$.

Pero reducir la comunicación a negocio sería, incluso para la propia comunicación, un mal negocio. La situación mediática que se ha producido en los últimos años en España, más que profundizar en el conocimiento de la realidad o en el análisis del empleo de la comunicación como instrumento de progreso, se ha convertido en un negocio-espectáculo de la realidad, sin fronteras, sin amparo cívico y sin límites.

12 ZALLO, R., El mercado de la cultura europea. Estructura económica y política de la comunicación. Donostia (Guipúzcoa), Gakoa, 1992,pp. 82-85. 
Se puede deducir, a través de los múltiples informes realizados sobre distintas empresas de telecomunicaciones y de informática, que, para éstas, hablar de contenidos culturales es hablar en términos económicos. La desregulación y la expansión de la cultura han dotado a las industrias culturales y comunicativas de un notable peso económico. Sin embargo, es necesario, además, comenzar a diferenciar las industrias culturales productoras de contenidos (empresas de telecomunicaciones, de radiodifusión) de las industrias suministradoras de soportes de materiales o equipos técnicos (empresas de instrumentos y materiales culturales, fotografía, instrumentos musicales, etc.), ya que éstas últimas quedan fuera del concepto de industrias culturales. La informática y la infraestructura de redes y comunicaciones, que constituyen el objeto de este apartado y de parte de este artículo, son tecnologías de la información y de la comunicación. Pero estas infraestructuras, por sí solas, no tienen sentido, y necesitan llenarse de contenidos y servicios para poder cobrar mayor importancia.

La información y la comunicación están relacionadas desde hace aproximadamente 60 años, fecha en la que inician su desarrollo, pero ha habido que esperar hasta los años 90 para superar la subestimación con que estas empresas trataban a los contenidos y servicios, y, pese a que resulta cada vez más evidente que una red de infraestructura sin contenidos y servicios es una red sin interés para los usuarios (sobre todo teniendo en cuenta que, sin contenidos ni servicios atractivos, no hay rentabilización posible de las infraestructuras). Hoy, con la llamada Sociedad de la Información y del Conocimiento, las empresas de infraestructuras de comunicación han ido poniendo el acento cada vez más en los contenidos y servicios, y además, son los motores clave de su expansión, crecimiento económico y de empleo.

Las empresas tecnológicas definen a los contenidos que circulan por las redes como bienes y servicios de valor añadidos a los que se puede acceder a través de Internet, sin necesidad de desplazarse de un lugar a otro, además de ser el motor de sus negocios. A este respecto Bustamante afirma: "los contenidos culturales y comunicacionales aparecen cada vez más como la clave estratégica de la Sociedad de la Información y como el nudo de la articulación de la economía, la cultura y la democracia en una concepción integral del desarrollo"13.

Sin embargo los contenidos siguen siendo, en muchos casos, una asignatura pendiente, y únicamente los contenidos de calidad harán que las redes y las nuevas tecnologías sean realmente útiles ${ }^{14}$. Los contenidos y su desarrollo son un material caro que precisa de gran volumen de uso para conseguir un retorno mínimo de la inversión. Además, el índice de fracasos en el mundo de las aplicaciones y

\footnotetext{
13 BUSTAMANTE. E, Industrias culturales, sociedad de la información y desarrollo, Conferencia en Santiago de Chile, Abril del 2000.

14 Véase, el interesante artículo sobre contenidos en Internet: Los contenidos de Internet: importancia y recomendaciones (David Prado Vázquez) (v. Referencias Electrónicas).
} 
contenidos es alto; como puede verse en el mercado de la televisión, estas inversiones implican un riesgo, y el modelo de exclusividad que hasta ahora conocíamos en Europa ${ }^{15}$ ha fracasado y debe dejar paso a la idea de comercialización de los productos como sucede en Estados Unidos, en caso de que se quiera evitar poner un freno al desarrollo de las industrias de los contenidos o distorsionar la competencia entre operadores de escala mundial muy distinta.

Los contenidos multimedia e interactivos, como los negocios, tendrán que enfocarse de diferente manera, pues las fuentes de ingreso serán muy distintas en cada uno de ellos (televisión digital, telefonía móvil e Internet).

La televisión digital, por su parte, no va a experimentar grandes cambios en su modelo de negocio, sus principales fuentes de ingresos son el pay per view (pago por visión), la publicidad y las cuotas de abono, que ocupan el tercer lugar de esta clasificación.

La publicidad, hoy la única fuente de ingreso de muchos sitios web, junto con la opción de pago por contenidos en Internet, que cuenta con una menor aceptación debido a la reticencia a pagar en un medio donde siempre ha imperado la cultura del todo gratis, y por último las cuotas de abono, no dejan de ser preocupantes en la problemática del desarrollo de contenidos de calidad.

En cuanto a las empresas dedicadas a los contenidos, la calidad de los productos y servicios, serán los principales factores a tener en cuenta, por lo que las empresas tecnológicas están utilizando los mismos patrones que las tradicionales, con una tendencia a integrar contenidos, distribución y redes.

Los contenidos por los que los usuarios están dispuestos a pagar ${ }^{16}$ están, según los expertos, aún por llegar, y serán el webcasting, el e-cinema, así como servicios de formación on-line; mientras que los que siguen despertando mayor interés son la comunicación interpersonal, el correo electrónico, los servicios de formación y educación, y los servicios relacionados con el juego y el ocio. Los servicios relacionados con la Administración Pública como los servicios de información, gestión, sanidad, etc., tienen un alto interés para los usuarios; sin embargo, estos no están dispuestos a pagar porque consideran que tienen derecho a acceder gratuitamente. La financiación de los contenidos será, entonces, a través de las cuotas de acceso a Internet.

\footnotetext{
${ }^{15}$ En el modelo europeo los productos televisivos no tienen ni un segundo ni un tercer mercado, desde el momento que son realizados por la propia empresa o por encargo de ella, y los derechos son para la propia empresa. No son productos concebidos para ser vendidos en el mercado por falta de una buena red comercial. Además, la relación coste-audiencia respecto a Estados Unidos está en inferioridad de condiciones por las dimensiones de los distintos países europeos.

${ }^{16}$ Para más información acerca del tema, se recomienda visitar las publicaciones de los resultados de lo realizado en el 1er Congreso On Line del Observatorio para la Cibersociedad: La problemática de la rentabilidad de los sitios de los diarios en Internet. (v. Referencias Electrónicas).
} 
Cultura y Medios...

\section{LA CULTURA EN LOS MEDIOS: LAS INDUSTRIAS CULTURALES}

La tercera perspectiva sobre cultura que nos interesa arranca de los medios mismos, de su estructura económica y de sus fuentes de financiación. Se caracteriza por tener los medios convencionales (prensa, revistas, radio, televisión y ahora Internet).

Esta industria de los medios, sin embargo, es cada día más una industria del negocio de la información y la comunicación, sobre todo desde mediados de los años 80 , y pone en evidencia cómo los distintos sectores culturales tradicionales (el cine, la música, los libros, los videojuegos, etc.), no tendrían relevancia económica, social y de mercado sin medios convencionales como la televisión. Por eso podemos decir que el negocio de los medios, de las industrias culturales, es principalmente el negocio de la industria de la televisión.

De ahí, según Bustamante, que la televisión se ha convertido en algo más que una industria cultural: "es la reina de las industrias culturales, somete a su dinámica a la práctica totalidad de las restantes industrias culturales de las que constituye un cliente capital muchas veces (cine, disco, espectáculo...) y siempre un escaparate de propaganda indispensable" ${ }^{, 17}$. O como dice Baudrillard: "La televisión, es el medio de los medios" ${ }^{18}$ y el paradigma de la transmisión en la cultura de masas, posibilita que los ciudadanos accedan, mucho más fácilmente que antes de la existencia de los medios, a obras teatrales, cine, conciertos, etc.

Para Bustamante, como las industrias culturales son un campo más para la consecución de beneficios, no es de extrañar la tendencia hacia la concentración y transnacionalización de las empresas de medios de comunicación. Muchas de estas industrias culturales han vivido tempranamente estos procesos de concentración en los países industrializados. Basta pensar en la prensa de muchos países europeos. en el cine estadounidense, pero también en el francés o el alemán; en las televisiones norteamericanas y de algunos países latinoamericanos; en el disco, etc. Los índices de concentración en cada rama y país resultan muy distintos. Las radios y las televisiones aparecen como sectores ampliamente controlados por los otros medios de comunicación de masas; el disco, como perteneciente al dominio de la radio, la televisión y el cine; el cine es un sector independiente de los otros medios de comunicación de masas. El fenómeno de la transnacionalización en las industrias culturales primero en el disco, luego en el cine, en los programas televisivos y la publicidad después, hay una larga historia de expansión internacional que parte de los grandes grupos estadounidenses como único poder, que luego se van extendiendo paulatinamente al resto de los países industrializados como Japón y Europa.

17 BUSTAMANTE, E. y ZALLO, R. (coords.), Industrias Culturales en España (grupos multimedias y transnacionales). Madrid, Akal, 1988

${ }^{18}$ BAUDRILLARD, J., La guerra del Golfo no ha tenido lugar. Barcelona, Anagrama, 1992. Para recabar más datos acerca de la perspectiva de Jean Baudrillard sobre los medios y en especial sobre la televisión, se recomienda su obra La guerra del Golfo no ha tenido lugar. 
Estas seis industrias, desde la perspectiva de Bustamante, las industrias creativas (libros, cine, disco) y los grandes medios de comunicación masivos (prensa, radio y televisión), suman la inmensa mayoría del peso económico de la cultura y la comunicación industrializada y mercantil, quedando fuera las actividades culturales clásicas, aunque ampliamente mercantilizadas en esta década (el teatro, los conciertos, la danza, etc.). "(...) Los cimientos indispensables para la era digital residen en las industrias culturales tradicionales, aunque sean parcialmente reconvertidas y adaptadas a los nuevos soportes y mercados. (...) Las industrias culturales juegan un papel cada vez más importante para la economía y el crecimiento del empleo, sin dejar nunca de ser esenciales para la equidad o imparcialidad y la cohesión social, para la democracia española (...). Además de ser el motor económico y de desarrollo de la Sociedad de la Información"19 .

En un recorrido como el que hacemos, que intenta, entre otras cosas, repasar el panorama cultural y comunicacional desde la Escuela de Frankfurt hasta la convergencia multimedia, resulta interesante señalar el siguiente párrafo de Timoteo, donde se hace una lectura de la televisión como zona de confluencia de los medios de comunicación, tecnologías y de la cultura:

"La actual industria de la información y comunicación es de hecho una convergencia de tres industrias de origen diverso, televisión, informática aplicada a los medios y telecomunicaciones aplicada a los medios, aglutinadas todas en torno a la pantalla de la televisión casera. La presencia, desde los 70 del pasado siglo, de un aparato de televisión al menos en todos los hogares de occidente cambió muchísimas cosas. Ese "punto de venta" en cada hogar servía como terminal en un sistema de distribución bastante directo de la oferta comercial, de la oferta política, del ocio y de todos los productos culturales convencionales. Fue naturalmente el sueño para los políticos, anunciantes, productores de películas, teatro, música, libros, organizadores de deportes de masas y de espectáculos de toda condición...

En la televisión convergen no sólo las tecnologías nuevas de la información y comunicaciones sino también todas las viejas aspiraciones de la industria cultural convencional. Es necesario por tanto, para entender lo que supone la convergencia en inf+com, referirnos no sólo a la coincidencia de tecnologías y redes sino también a esa convergencia de concepciones en torno a los contenidos, sus desarrollos e industrias ${ }^{20}$.

El hecho de que se produzca, en la televisión, una convergencia de los otros medios, hace que ésta se transforme en un punto de venta que soporta varios mercados: el de la información, el de la comunicación política, el de la comunicación comercial y el de productos de entretenimiento. Buena parte de ellos se "venden" bajo los conceptos nobles de información, de formación y de educación (cultura). Informar, formar y entretener es el más clásico de los lemas de la televisión" ${ }^{21}$.

19 BUSTAMANTE, E. (coordinador), Comunicación y cultura en la era digital: Industria, mercados y diversidad en España. Barcelona, Gedisa, 2002, p. 24

${ }^{20}$ TIMOTEO ÁlVAREZ, J., Gestión de Poder Diluido. La construcción de la sociedad mediática (1989- 2004). Madrid, Pearson, 2005, p.72

${ }^{21}$ Ibidem, 73 
Las dimensiones del negocio de esta convergencia de medios particularmente, desde Timoteo, en la televisión, terminan acaparando todos los componentes que el autor introduce en su tipología:

- "Información en su doble acepción de noticias y titulares y de datos y referencias acumulados en bases, archivos y fuentes documentales

- Entretenimiento en su múltiple acepción de programas de ocio (deporte, magazines, talk show,...), cine, videojuegos, ocio on-line, etc.

- Libros convencionales y nuevos (libro-disco, Internet,...)

- Música en discos, Internet...

- Comunicación comercial, publicidad y alternativas ("below the line")

- Comunicación política e institucional”22.

Para concluir diremos que aquello a lo que Timoteo denomina la industria Inf +Com, que son las clásicamente llamadas Industrias Culturales, surgieron en los países más avanzados económicamente, y ahí es donde han triunfado en todos sus sectores: cine, radio, televisión, discográficas, editorial, publicidad se instalan, de este modo, entre los diez primeros sectores de mayor interés económico en los países más avanzados de Europa, y suponen un 10\% del producto bruto interno de dichos países (alrededor del 6\% en España).

\section{BIBLIOGRAFÍA:}

ABELLÁN, J.L., Industria Cultural en España. Madrid, Cuadernos para el Diálogo, 1975. AGUADERO FeRnÁndEZ, F., La Cultura Audiovisual. Madrid, Ciencia 3, 1997.

ANVERRE, A. y otros, Industrias Culturales: El futuro de la cultura en juego. Méjico, Fondo de la Cultura Económico y París, Fundesco, 1982.

ARNANZ, C.M., Negocios de televisión: transformaciones del valor en el modelo digital. Barcelona, Gedisa, 2002.

BAUDRILLARD, J., La guerra del Golfo no ha tenido lugar. Barcelona, Anagrama, 1992. BAUDRILLARD, J., Cultura y simulacro. Barcelona, Kairós, 1978.

BERNAL RODRIGUEZ, M. (coord.), Cultura Popular y Medios de Comunicación: Una aproximación desde Andalucía. Sevilla, Comunicación Social, 2002.

BELL, D. y otros, Industria Cultural y Sociedad de Masas. Venezuela, Monte Ávila Editores, 1969.

BELL, D., El advenimiento de la sociedad industrial. Madrid. Alianza. 1994. 
BORDIEU, P., Sobre la televisión. Barcelona, Anagrama, 2000.

BUENO, G., "Cultura". Barcelona, Basilisco 4, 1978.

BUSTAMANTE, E., Los amos de la información en España. Madrid, Akal, 1982.

BUSTAMANTE, E. y ZALLO, R. (coords.), Industrias Culturales en España (grupos multimedia y transnacionales). Madrid, Akal, 1988.

BUSTAMANTE, E. (coordinador), Comunicación y cultura en la era digital: Industria, mercados y diversidad en España. Barcelona, Gedisa, 2002.

DIRCOM, Anuario de la Comunicación, directivos de la Comunicación. Madrid, Dircom, 2003.

ECO, U., Apocalípticos e integrados. Barcelona, Lumen, 1993.

ESCOBAR DE LA SERNA, L., Comunicación, Información y Cultura de Masas. Madrid, Secretaría General Técnica del Ministerio de Cultura, 1980.

FEATHERSTONE, M., Cultura de consumo y postmodernismo. Buenos Aires, Amorrortu editores, 1991.

GOLDEROS, A., La tecnologías multimedia en la comunicación social en Comunicación Social. Tendencias. Las nuevas fronteras de los medios. Informes anuales de Fundesco, Madrid, 1995.

HORKHEIMER, M. y ADORNO, Th., Dialéctica del Iluminismo; La Industria Cultural. Iluminismo como mistificación de las masas. Buenos Aires, Sudamericana, 1988.

INFORME ANUAL, Telecomunicaciones y las Tecnologías de la Información. Madrid, Grupa Zeta, 1999, 2001, 2002.

INFORME ANUAL DE LA COMUNICACIÓN. Madrid, Grupa Zeta, 1997- 2002.

LAZARSFELD, P.F. y MERTON, R. K., Comunicación de masas, gusto popular y acción social organizada. Buenos Aires, Centro Editor de América Latina, 1977.

MACDONALD, D., Masscult y Midcult (artículo), en La industria de la cultura, Madrid, (Comp.) Alberto Corazón.

mATtelaRT, A. y M., Historia de las Teorías de la Comunicación. Barcelona, Paidós Comunicación, 1997.

MILLÁN PAREDES, T., Grandes espacios tecnológicos \& Grandes vacíos televisivos: Análisis del comienzo de la televisión por cable en España. Badajoz, Marcipa S.L. 1994.

REIG, R., Medios de Comunicación y Poder en España: Prensa, radio, televisión y mundo editorial, Barcelona, Paidós, 1998.

RODRIGo ALSINA, M., Teorías de la Comunicación. Barcelona, Aldea Global, 2001.

RODRIGo ALSINA, M., Los Modelos de la Comunicación. Madrid, Tecnos, 1995.

RODRÍGUEZ PASTORIZA, F., Cultura y televisión: una relación de conflicto. Barcelona, Gedisa, 2003.

SCHILLER, F., Escritos sobre estética. Madrid, Tecnos, 1991.

SUBIRATS, E., Culturas virtuales. Biblioteca nueva, 2001. 
TELECOMUNICACIONES Y LAS TECNOLOGÍAS DE LA INFORMACIÓN. Madrid, Grupo Zeta, 1999, 2001, 2002.

TELEFÓNICA, La Sociedad de la Información en España, Presente y Perspectivas. Madrid, Grupo Zeta, 2000-2002.

TENDENCIAS, Comunicación Social, Informes Anuales. Madrid, Fundesco, 2004,2005,2006

TIMOTEO ÁLvAREZ, J., Gestión de Poder Diluido. La construcción de la sociedad mediática (1989- 2004). Madrid, Pearson, 2005.

VERDÚ, V. El estilo del mundo: la vida en el capitalismo de ficción. Barcelona, Anagrama, 2003.

WILLIAMS, R., Sociología de la cultura. Barcelona, Paidós, 1994.

ZALLO, R., Industrias y políticas culturales en España y el País Vasco. Bilbao, Servicio Editorial de la Universidad del País Vasco, 1995.

ZALLO, R., El mercado de la cultura europea. Estructura económica y política de la comunicación. Donostia (Guipúzcoa), Gakoa, 1992.

Artículos:

Murciano, M. (1990), "Cuestiones Metodológicas en la Investigación sobre Industrias Culturales". Análisi, № 13, págs. 15-26.

Referencias Electrónicas:

Prado Vázquez, David. Los contenidos en Internet: importancia y recomendaciones, [en línea], España, Microsoft, Centro para Empresas y Profesionales. Dirección URL: http:/ /www.microsoft.com.

(Recibido el 14-03-06, aceptado el 3-06-06) 